\title{
Laparoscope Assisted Embryo Transfer and Conception Rate in Farm Rambouillet Ewes
}

\author{
Anil Kumar Pandey*, Utsav Sharma, Sudhir Kumar, Sharad Kumar, \\ Nishi Pande, Anil Kumar Kaul, S. E. H.Andrabi and Jaan Mohammad Wani
}

Division of Veterinary Gynaecology and Obstetrics, Faculty of Veterinary Sciences and Animal Husbandry, R. S. Pura, Sher-e-kashmir University of Agricultural Sciences and Technology of Jammu-181102

*Corresponding author

Keywords

Laparoscope,

Embryo transfer,

Bred rambouillet Ewes

Article Info

Accepted:

26 May 2020

Available Online:

10 June 2020

\section{A B S T R A C T}

The present study was performed to assess the usefulness of laparoscope in the embryo transfer programmes in sheep and to evaluate conception rate after single, double and triple embryo transfer in farm bred rambouillet ewes. A total of 21 freshly collected embryos were transferred in 11estrus synchronized ewes to yield nine lambs. The conception rate of single, twin and triplet embryo transfer was $66.67 \%, 50 \%$ and $100 \%$, respectively with the lambing rate was $0.00 \%, 66.67 \%$ and $100 \%$, in the respective groups. The embryo survival rate was $100 \%$ and $80 \%$ in twin and triplet embryo transfers. It was concluded that laparoscope is very useful tool in detection of ovulation and selection of suitable ewes for embryo transfer. Aid of laparoscope in embryo transfer programme reduces surgical risks and minimizes total time in embryo transfer.

\section{Introduction}

Sheep is a multi-facet utility animal reared mainly for the flesh and fibers, though it also produces some milk and has religious values too. Its contribution in the rural economy is important particularly in the mountainous areas of the country. Easy rearing under broad environmental conditions, short generation cycles and a high fecundity are the characters which need to be properly exploited to enhance the contribution of sheep in the development of Indian economy. Embryo transfer is a technique by which elite female animals are superovulated to produce embryos which are collected from uterus prior to implantation and are transplanted in to the reproductive tract of synchronized recipient females to bear gestation and give birth of offspring (Gibbons and Cueto, 2011). It is a unique tool and has opened up many possibilities in enhancing production potential 
in sheep by shortening the generational interval. Use of laparoscope minimizes surgical trauma and chances of post surgical adhesion (Gebrehiwot et al., 2018). Various researchers had observed adverse effect of multiple pregnancies as lower birth weight (Alexander, 1974) and high mortality after birth (Huffman et al., 1985) leading to retarded growth and poor performance in postnatal life (Brown and Radziewic, 1998).

Ovine embryo transfer has not being extensively used in India, since CSWRI (ICAR) has made pioneering efforts on superovulation and surgical embryo transfer in the native Gargole sheep (Naqvi et al., 2006). Transfer of multiple embryos in recipient reduces the cost during care of recipients, thus is economical, though various reports available on this are conflicting (Naqvi et al., 2007) and finally requires to be tested for the specific sheep breed used. Sporadic trials have been made to superovulate ewes in the other parts of the country but this technology is yet to be adopted at sheep breeding farms. This work was performed to evaluate the usefulness of laparoscope in the embryo transfer programmes and to evaluate conception rate after single, double and triple embryo transfer in farm bred rambouillet ewes.

\section{Materials and Methods}

The present study was carried at Embryo Transfer Technology (ETT) laboratory at Govt. Sheep Breeding Farm (SBF), Sheep Husbandry Department of Jammu, Panthal, District Reasi, lying in the subtropical zone of Jammu and Kashmir, located at the latitude of $32^{\circ} 58^{\prime} 29^{\prime \prime} \mathrm{N}$ and longitude of $74^{\circ} 58^{\prime} 35^{\prime \prime} \mathrm{E}$ and 1671 meters above the mean sea level. The experiment was conducted during breeding season (August to November) months of the year 2015, 2016 and 2017, with environmental temperature fluctuating between a minimum of $8 \mathrm{oC}$ and a maximum of $30^{\circ} \mathrm{C}$. Eighty parous cyclic crossbred ewes aged between 6 and 8 years, in their $2^{\text {nd }}$ to $4^{\text {th }}$ parity, weighing between 40 and $50 \mathrm{~kg}$ and in good body condition (score $>3$ out of 5) were selected for the experimentation.

All the ewes were kept under loose housing system in the animal sheds having concrete flooring, asbestos roofing and sufficient space for the free movement in a clean and hygienic condition. They were grazed daily from 07:00 $\mathrm{AM}$ to 06:00 PM on green pastures interspersed with seasonal shrubs with water ad libitum. Additionally each ewe was fed daily $6 \mathrm{~kg}$ green/dry fodder (Oat/maiz/ barseem) and $500 \mathrm{gm}$ concentrate mixture. All the ewes were examined using an ultrasound scanner to rule out pregnancy and any pathological defects of genitalia and ovarian abnormalities.

\section{Estrus synchronization of donor and recipient ewes}

All donor and recipient ewes were synchronized for estrus using polyurethane sponge impregnated intravaginal progesterone implant, kept in situ for 12 days. The recipient ewes received injection serum gonadotropin (eCG, Folligon, Intervet) @ 200 IU just after withdrawal of progesterone sponge while donor ewes received eCG at the time of first FSH injection. Estrus detection in donor and recipient ewes was carried out using an appronized ram an interval of $3 \mathrm{hrs}$ after removal of the implant. Donor ewes were bred with quality ram while recipient ewes were strictly segregated to prevent breeding.

\section{Embryo production}

Embryos were produced from superovulated donor ewes using purified porcine FSH given in six tapering dose protocol and eCG, injection given at the start of first FSH given 
on day 10 after application of progesterone sponge. Donor ewes were treated in two FSH dose groups with/without hCG hormone given $24 \mathrm{~h}$ after removal of implant, thus making four groups Group-I (80 mg FSH), Group-II (80 mg FSH+ $500 \mathrm{mg}$ hCG), Group-III (100 mg FSH), Group-IV (100 mg FSH+ 500 mg hCG). On observation of estrus donor ewes were hand mated once and further same breeding ram was allowed to accompany over night with them.

Embryo collection was performed surgically after 5-6 days of breeding date in donor ewes. Retrograde flushing of the uterine horns were done using flushing media (Euroflush, IMV Technologies) with the help of IV cannulla introduced near the bifurcation of uterine horns. The washings were collected through catheterization of fallopian tubes and collected in sterile beaker. Searching, isolation, evaluation and gradation of embryos were performed under stereo zoom microscope (Olympus, Japan) at 200X and were classified morphologically as per Gibbons and Cueto (2011).

\section{Laparoscopy and embryo transfer}

Suitable recipient ewes that have synchrony in onset of heat within $12 \mathrm{hrs}$ with the donor were selected for embryo transfer. For evaluation of site of ovulation a $2.5 \mathrm{~mm}$ diameter and $30 \mathrm{~cm}$ length with 300 forwardoblique rigid laparoscope telescope (KARL STORZ) was used. Pneumoperitoniun using 4-5 $\mathrm{L} \mathrm{CO}_{2}$ gas was achieved using by KARL STORZ- ENDOFLATOR device if required during the examination.

Ewes were restrained in dorsal recumbency on a special designed lap cradle with all the four legs firmly secured. Abdominal area anterior to udder was shaved and scrubbed with Savlon solution, dried with sterile gauge and sprayed with $70 \%$ alcohol for sterilization of clean skin. Sedation was achieved using Inj.xylazine @ 0.29 mg per $\mathrm{kg}$ body weight and local anesthesia by subcutaneous infiltration of Inj. lignocane 2\% $(\sim 5 \mathrm{ml})$ at the line of incision, $5-7 \mathrm{~cm}$ anterior to udder and 3-4 $\mathrm{cm}$ each side of the mid ventral line. Endoscope was sterilized by dipping in $70 \%$ alcohol solution followed by rinsing with double distilled water in between each examination.

Two small $(2 \mathrm{~cm})$ incisions using angular blade were made in the skin, approximately 46 inches in front of the udder, on each side of midline avoiding blood vessels. Trocar and trocar sleeve for the laparoscope were inserted on the left side of midline by sliding it under the skin about one inch before inserting it into the peritoneal cavity, avoiding puncturing blood vessels or other structures. Trocar was removed as soon it entered in the peritoneal cavity. Insufflation of peritoneal cavity was done for better visualization if required using pneumoperitoneum apparatus.

Laparoscope was inserted through trocar sleeves to observe the reproductive tract. Manipulation probe was inserted through second incision and its entry viewed into peritoneum through the laparoscope. With the manipulating probe it was easier to bring the uterine horn under field of vision and observe surface structures on the ovaries (Fig. 2). Locally modified atraumatic Allis's forceps were used to hold one of the uterine horns for lifting it up to the outer surface opening for better visualization of the horn with naked eye for embryo transfer.

Embryos were loaded in tomcat catheter in between air spaces attached to $1 \mathrm{ml}$ syringe. Ovaries were viewed through laparoscope with the aid of manipulating probe and uterine horn ipsilateral to the CL was gently lifted to the surface of skin and held between thumb and forefinger. An aperture was made in the 
uterine horn, 1/3rd towards ovary with a small conical trocar and embryo loaded catheter was inserted into lumen of uterus towards uterotubal junction followed by embryo deposition (Fig. 3).

After suturing the incision site using catgut (no. 1) for muscles and nylon thread for skin, Betadine ointment was applied at the sutured site. Inj. Streptopenicillin (Dicrysticin, Sarabhai Zydus, India) @ 500 mg was given just prior to laparoscopy and continued for 5 days BID along with Inj. meloxicam (Melonex; Intas Pharma., India) @15 mg/ ewe SID for 3 days. Ewes were placed in recovery pens and sutures removed after 8-10 days post surgery.

Recipient ewes post 30-40 days of embryo transfer were scanned with ultrasound machine (Prosound 2, Toshiba Aloka) using $5 \mathrm{MHz}$ transabdominal sector probe for presence of signs of pregnancy i.e. placentomes and fetus with fetal fluid.

\section{Results and Discussion}

The results obtained from the four recipient groups after embryo transfer, are presented in the table 1, the success rate after embryo transfer shows the effectiveness of laparoscope use in this study. It is evident from the results that conception rate of triplet embryo transfer was highest (100\%) with high lambing rate $(100 \%)$. The conception rate of single embryo (group-I) and twin embryo (group-II) transfers were also satisfactory (66.6\% and 50\%, respectively). Loss in conception occurred due to abortion occurring at day 45 and 140 days of gestation period under the group I and no lambing occurred in single embryo transfer, while one of the recipients in the group II bearing twin fetuses died unfortunately due to wild animal attack (Fig. 5). These results are quite satisfactory and are better than the previous reports of $29 \%$ to $65 \%$ pregnancies and $46 \%$ -
$80 \%$ lambing after embryo transfer in sheep (Ishwar and Memon, 1996; Gibbons et al., 2019; Folchet et al., 2000; Dattena et al.,2000). Brown and Radziewic (1998) reported higher pregnancy rate after transfer of twin (64\%) and single (39\%) in vitro derived embryos. Variations in the conception and lambing rate depends on various factors such as the developmental stage of embryo at the time of transfer, synchronization between donor and recipient, age of embryo donor, embryo storage, and embryo production method (in vivo or in vitro) (Thompson et al., 1995; Dattena et al., 2000).

The present study transferred only excellent and good quality embryos (Fig. 1) which has resulted high conception rate. The high conception rate obtained in this experiment shows precision in quality and selection of transferable grade (Grade-I and Grade-II) embryos (Angela et al., 2006). These results are comparable with the reports of Rizzo et al., (2012), who observed lambing rate of $83.6 \%$ and survival rate of $63 \%$ after embryo transfer. They also reported that conception rate in multiparous recipient ewes were better than nulliparous and for best results two embryos should be transferred to recipient ewes having more than two corpora lutea. The high gestational loss after single embryo transfer in our experiment is mainly due to lower number of animals used in this group. Gibbons et al., (2011) suggested single embryo transfer as the viability of fetus is equal to the twin embryo transfer, around $41 \%$ and $50 \%$ for transfer of morulae and blastocysts, respectively. Higher perinatal mortality occurs even under the extensive conditions and ultimately penalize the final yields of the embryo transfer though twin and triplet embryo transfer reduces maintenance cost on recipients (Naqvi et al., 2007). Fernandez Abella (2015) observed 75\% and $90 \%$ of lamb survival for twin and single lambs, respectively. The lamb survival observed in our research was $100 \%$ in twin 
embryo transfer while it was $80 \%$ in the triplet transfer group (Table 1, Fig. 4). In previous reports greater lamb survival for single lamb (80\%) than for twin lambs (43\%) was observed by Brown and Radziewic (1998) from IVF derived embryos, while Naqvi et al., (2007) suggested transfer of triplets for economic concerns.

Table.1 Embryo transfer and lambing in different recipient groups

\begin{tabular}{|c|c|c|c|c|c|c|c|c|}
\hline 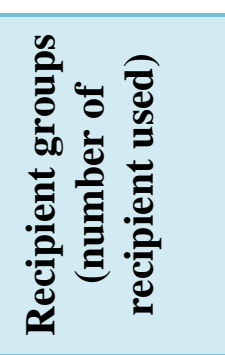 & 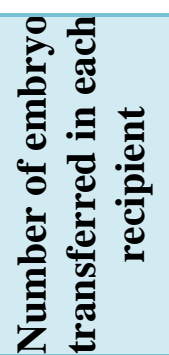 & 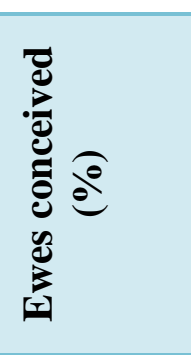 & فे & 跑 & 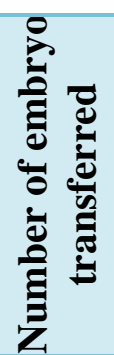 & 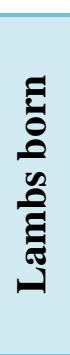 & 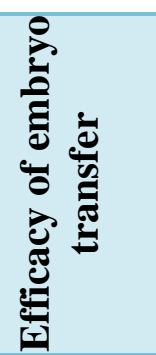 & 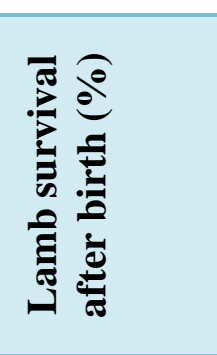 \\
\hline Group-I (3) & 1 & $2(66.67 \%)$ & $0^{*}$ & $2(100 \%)^{*}$ & 3 & 0 & $0.00 \%$ & - \\
\hline $\begin{array}{c}\text { Group-II } \\
(6)\end{array}$ & 2 & $3(50.00 \%)$ & $2 / 3(66.67 \%)^{\#}$ & $1(33.33 \%)^{\#}$ & 12 & 4 & $33.33 \%$ & $4(100.00 \%)$ \\
\hline $\begin{array}{l}\text { Group-III } \\
\text { (2) }\end{array}$ & 3 & $2(100 \%)$ & $2 / 2(100 \%)$ & $0(0 \%)$ & 6 & 5 & $83.33 \%$ & $4(80.00 \%)$ \\
\hline Total (11) & - & $7(63.64 \%)$ & $4 / 7(57.14 \%)$ & $3(42.86 \%)$ & 21 & 9 & $42.86 \%$ & $8(88.89 \%)$ \\
\hline
\end{tabular}

"Both conceived ewes aborted at 45 day and 140 days of gestation.

\#One animal unfortunately killed in wild animal attack bearing twin fetuses

Fig.1 Transferable grade sheep embryo (morula stage) 


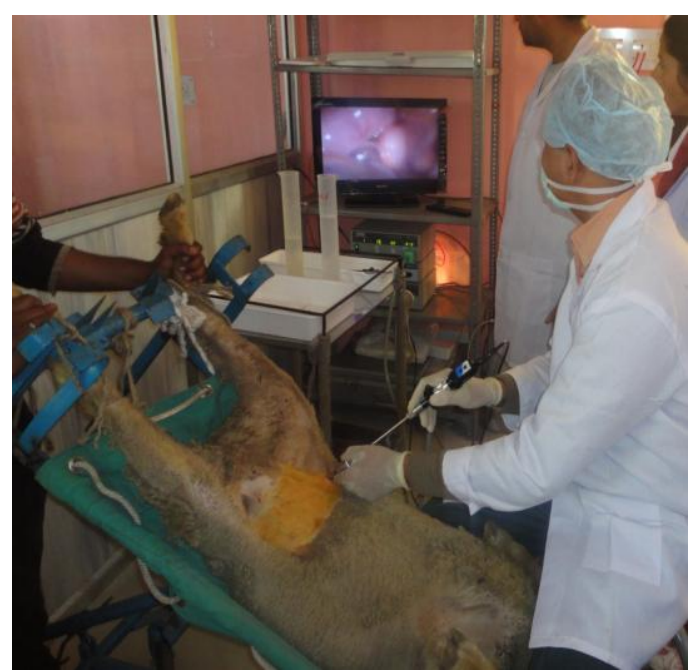

Fig.2 Laparoscopic evaluation of ovulation in recipient ewe

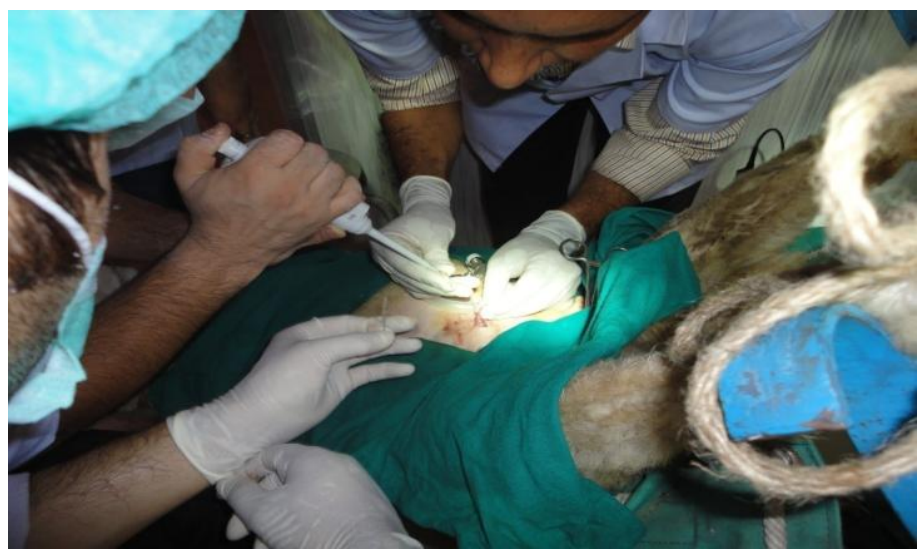

Fig.3 Laparoscope assisted embryo transfer (loaded in tomcat catheter)
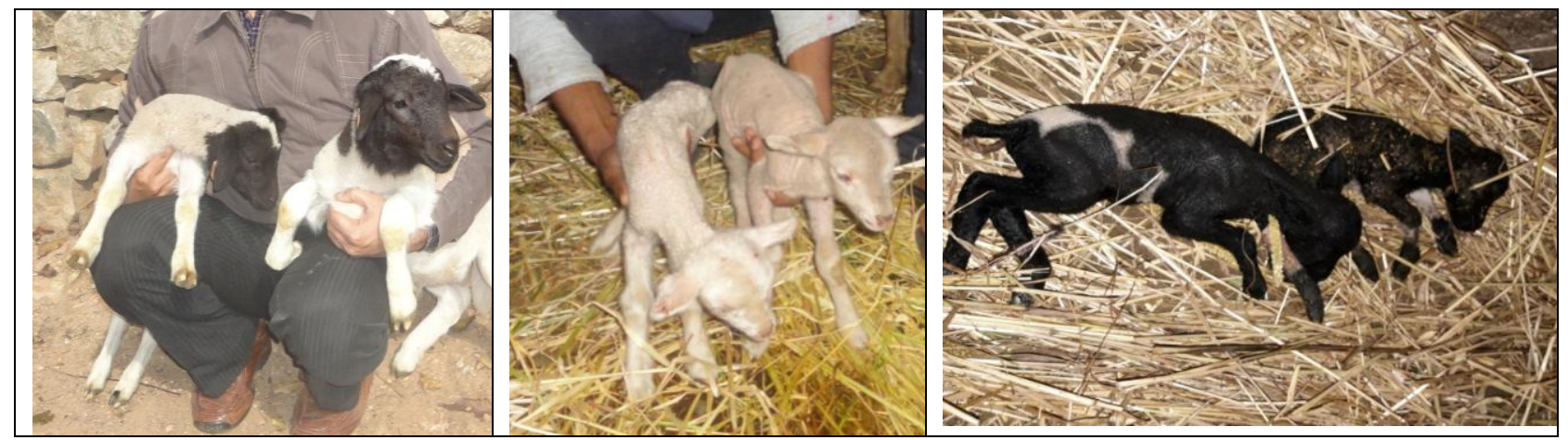

Fig.4 Lambs born after embryo transfer 


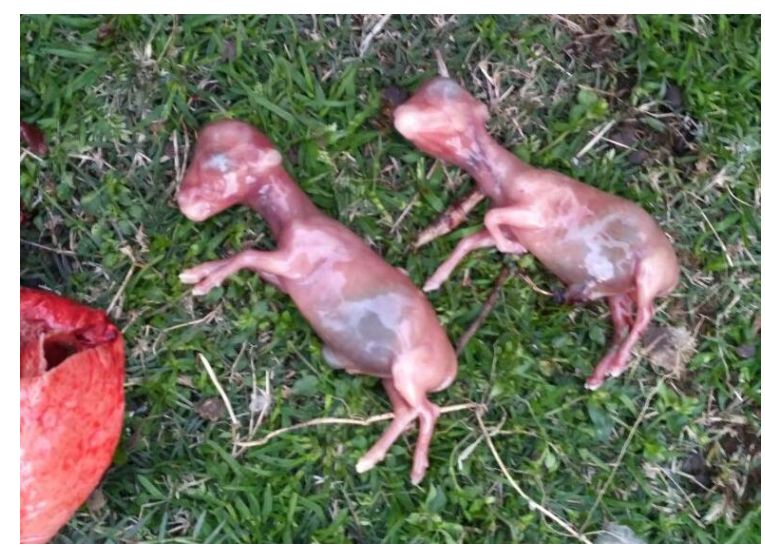

Fig.5 Fetuses recovered after postmortem of recipient ewe died in wild animal attack

There are a great number of environmental factors that influence reproduction (Bronson, 1985) and many of them influence prenatal survival, besides this various maternal and embryonic factors accrues to increased embryonic death after embryo transfer (Wilmut et al., 1986). The embryo transfer efficacy calculated on the basis of lamb born out of total embryos transferred was $42.86 \%$ in this experiment is comparable with results of Naqvi et al., (2007), though it is lower than global standard (Gebrehiwot et al., 2018) and leaves scope for further investigations in refining this technique.

We can conclude that the pregnancy rate following fresh embryo transfer in recipient ewes in the sheep farm is $63.64 \%$. The lambing rates of conceived ewes are $57.14 \%$ with $42.86 \%$ gestational loss. The efficacy of embryo transfer was high $(83.33 \%)$ in triplet embryo transfer, whereas lamb survival after birth was highest $(100 \%)$ in the twin embryo transfer. Laparoscope was effectively used in embryo transfer programme at farm level. High gestational loss after embryo transfer requires much attention and needs special care of pregnant ewes to make the programme efficient and viable. The embryo transfer efficiency obtained after twin and triplet embryo transfer in this experiment is as par global embryo transfer efficiency and recommends its use for the sheep farm.

\section{Acknowledgements}

The authors are grateful to the Sheep Husbandry Department of Jammu and SKUAST-J for providing necessary support.

\section{Funding}

Department of Animal Husbandry, Dairying and Fisheries, Ministry of Agriculture, Govt. of India.

\section{References}

Alexander, G. 1974. Birth Weight of Lambs: Influences and Consequences. Associated Scientific Publishers, New York, pp. 215245.

Angela S. Prefac G. Paul T. Alexandru S. Dana T. 2006. Evaluation of Sheep Embryo Quality by Morphologic Methods Advantages and Disadvantages. Journal of Tekirdag Agricultural Faculty 3(1):68-70.

Bronson, F.H. 1985. Mammalian reproduction: an ecological perspective. Biol. Reprod. 32, 1-26.

Brown, B.W., Radziewic, T. 1998. Production of sheep embryos in vitro and development of progeny following single and twin embryo transfer. Theriogenology 49, 1525-1536.

Dattena, M., Ptak, G., Loi, P., Cappai, P. 2000. Survival and viability of vitrified in vitro 
and in vivo produced ovine blastocysts. Theriogenology 53, 1511-1519.

Fernandez Abella D. 2015. Mortalidad neonatal de corderos. Tecnologías reproductivas bovinas y ovinas. Editorial Hemisferio Sur, Montevideo, Uruguay. pp.27-46.

Folch, J., Olivera, J., Aguilar, B., Alabart, J. L., Sanchez, P., Echegoyen, E., Cocero, M. J. 2000. Resultados obtenidos em la transferência de embriones dentro del programa genético de la U.P.R.A. carnes Oviaragon. In: Resumenes de las XXV Jornadas SEOC; pp. 559-561.

Gebrehiwot, H. W., Tsegaye, Y. and Gebrekidan, B. 2018. A Review on Current Status of Embryo Transfer Technology in Sheep and Goats. EC Veterinary Science 3.1: 250-259.

Gibbons, A. and Cueto, M. 2011. "Embryo transfer in sheep and goats". Training manual. Bariloche experimental station, National institute for agricultural technology, Argentina: 11-57.

Gibbons, A., Bruno-Galarraga, M., Fernandez, J., Gonzalez-Bulnes, A. and Cueto, M. 2019. Vitrified embryo transfer in Merino sheep under extensive conditions. Anim. Reprod., v.16, n.2, p.297-301.

Gibbons, A. E., Cueto, M. I. and PereyraBonnet, F. P. 2011. A simple vitrification technique for sheep and goat embryo cryopreservation. Small Rumin Res, 95:61-64.

Huffman, E. M., Kirk, J. H. and Pappaioanou, M. 1985. Factors associated with neonatal lamb mortality. Theriogenology 24, 163 171.

Ishwar, A. K. and Memon, M. A. 1996. Embryo transfer in sheep and goats: A review.
Small Ruminant Research. 19. 35-43.

Naqvi, S. M. K., Joshi, A., Kumar, D., Gulyani, R., Maurya, V. P, Saha, S., Mittal, J. P. and Singh V. K. 2007. Developmental competence, birth and survival of lambs following transfer of twin or triple embryos of dwarf size prolific donor into large size non-prolific recipient sheep. Journal of Cell and Animal Biology Vol. 1 (5), pp. 082-086.

Naqvi, S. M. K., Joshi, A., Gulyani, R., Kumar, D., Kolte, A. P., Kumar, et al., 2006. Production of prolific microsheep by embryo transfer into large non-prolific sheep. Veterinary Record, 159(16), 522526.

Rizzo, H., Francois, D., Fassier, T., Guitton, E., Baril, G., Cognie, J., Fatet, A., Guignot, F., Mermillod, P., Petit, J. P., Beckers, J. F., Remy, B., Foucras, G. and Meyer, G. 2012. Transferência de embriões como ferramenta para formação de rebanho experimental ovino e análise dos fatores que podem maximizar a multiplicação do plantel. Rev Bras Reprod Anim, 36:62-65.

Thompson, J. G., Gardner, D. K., Pugh, P. A., McMillan, W. H., Tervit, H. R. 1995. Lamb birth weight is affected by culture system utilized during in vitro preelongation development of ovine embryos. Biology of Reproduction.53:1385-1391.

Wilmut, I., Sales, D. I., \& Ashworth, C. J. 1986. Maternal and embryonic factors associated with prenatal loss in mammals. Reproduction, 76(2), 851-864.

\section{How to cite this article:}

Anil Kumar Pandey, Utsav Sharma, Sudhir Kumar, Sharad Kumar, Nishi Pande, Anil Kumar Kaul, S. E. H. Andrabi and Jaan Mohammad Wani. 2020. Laparoscope Assisted Embryo Transfer and Conception Rate in Farm Rambouillet Ewes. Int.J.Curr.Microbiol.App.Sci. 9(06): 3605-3612. doi: https://doi.org/10.20546/ijcmas.2020.906.424 